\title{
THE APPLICATION OF NEW DU PONT/USA/COPPER COMPOSITION FOR MANUFACTURING OF THICK-FILM MICROWAVE LOW LOSS RESONATORS ON L AND X BAND ${ }^{\dagger}$
}

\author{
JANUSZ J. GONDEK, MAREK A. WOJCICKI and JAN KOPROWSKI
}

University of Mining and Metallurgy, Department of Microelectronics Institute of Electronics ul. Czarnowiejska 78, 30-054 Krakow, Poland

(Received, March 27, 1981; in final form June 25, 1981)

\begin{abstract}
The applicability of the various copper compositions to the production of thick-film microwave devices has been examined. The results of this work are presented in this paper. The paper presents criteria and computer programs for thick-film microwave integrated circuits. The investigations of asymmetrical striplines, stripline and circular resonators, microwave filters etc., have been used as a basis. The circuits were examined within the frequency band of 1-12 GHz. Based on the measurement results and the statistical analysis of the parameters of microwave integrated circuits, interesting conclusions concerned with the applications of thick-film techniques to microwaves have been drawn. The results obtained have been compared with other work and new mathematical models have been prepared. Finally the future development of microwave integrated circuits has been commented on.
\end{abstract}

\section{INTRODUCTION ${ }^{1,2}$}

Microwave integrated circuits have been produced so far by the use of hybrid and monolithic techniques. Circuits working in the frequency band $1-35 \mathrm{GHz}$ are made almost exclusively by the use of the hybrid techniques, particularly the thin-film technique.

However the last ten years have witnessed a considerable development of thick-film technology, and the leading firms have produced a new series of pastes for screening. The American Company Du Pont has produced a series of copper pastes with high conductivity which has created new possibilities for the application of thick-film technology. The purpose of the present paper is to present results showing the usefulness of these pastes in the production of thick-film microwave circuits (MICs).

\section{LOSSES IN THICK-FILM RESONATORS ${ }^{3,4}$}

Total losses in thick-film strip resonators are made up by losses taking place in the conductive film $\alpha_{d}$ and losses in the dielectric $\alpha_{d}$. For most substrate materials, $\operatorname{tg} \delta$ is of the order $10^{-4}$ and in such case losses the conductive films $\alpha_{c}$ are decisive in determining total

$\nmid$ Paper originally presented at the MELECON 81 Conference, Tel Aviv, Israel, May 24-28, 1981. attenuation. Losses in conductive films depend mainly on the sheet resistance, $R / \square$ of the conductive paste used. The relation between unit attenuation of ASL strips and the sheet resistance $R / \square$, is given in Figure 1 .

One can see that a change in sheet resistance $R / \square$ by $+40 \%$ - a case met with in practice-causes a change in unit attenuation by $+18.7 \%$. The lowest values of attenuation are obtained for conductive pastes with $R / \square<3 \mathrm{~m} \Omega$. This condition is met by the DU PONT copper pastes with $R / \square=1,3 \mathrm{~m} \Omega$, e.g. DP9922 and DP9925. Theoretical values of attenuation $\alpha=f(f)$ for a few Du Pont conductive pastes, computed by means of various mathematical models $(2,3)$, are given in Figures 2-4.

It can be shown that attenuation computed by means of a model assuming homogeneous current density is greater than that computed by means of the formulas obtained by R. A. Pucel ${ }^{2}$ and M. V. Schneider ${ }^{2}$. The lowest values of attenuation are obtained by $R$. A. Pucel's method ${ }^{2}$, and the highest ones by the method assuming homogeneous current density in ASL strips (2). The present authors showed in ${ }^{2,3}$ that M. V. Schneider's mathematical model best approximates the actual attenuation characteristics of thick-film ASL. As can be seen in Figures 2-4, the lowest values of attenuation are displayed by ASL's printed with copper pastes.

These pastes are usually less expensive than gold pastes, e.g. DP9791, and therefore are very interesting 


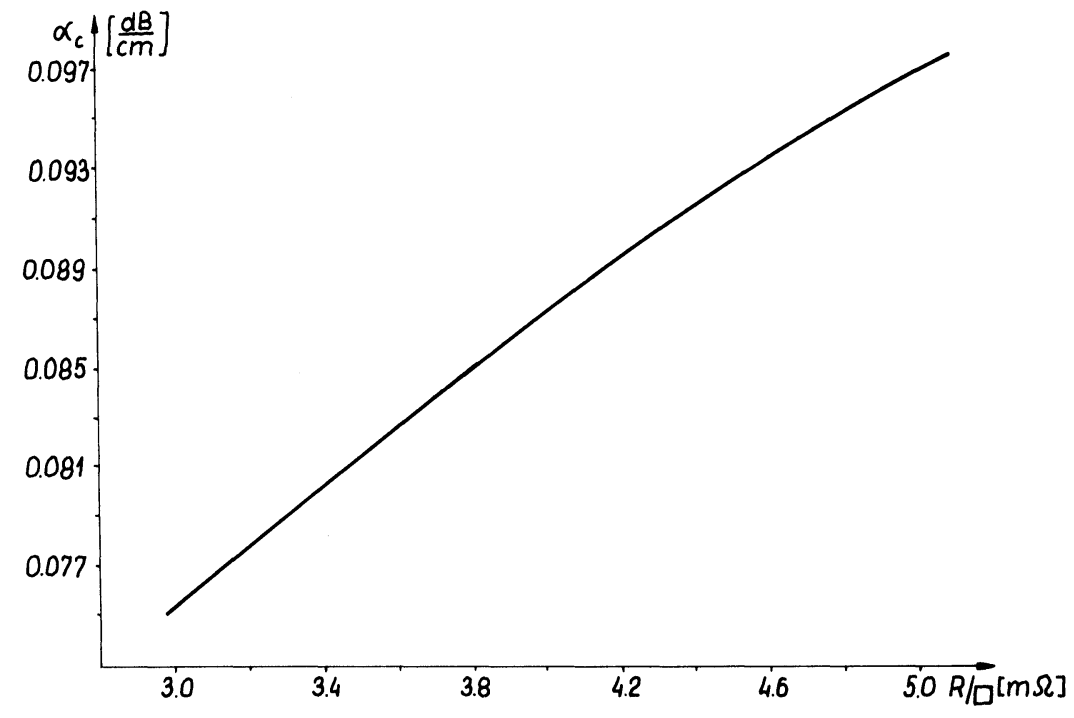

FIGURE 1 The relation between unit attenuation and sheet resistance $R / \square$, for the model of homogeneous current density in ASL strips. Substrate $96 \% \mathrm{Al}_{2} \mathrm{O}_{3}, \varepsilon_{r}=0.5, Z_{0}=50 \Omega, h=0.5 \mathrm{~mm}, t=18 \mu \mathrm{m}, f_{0}=2 \mathrm{GHz}$.

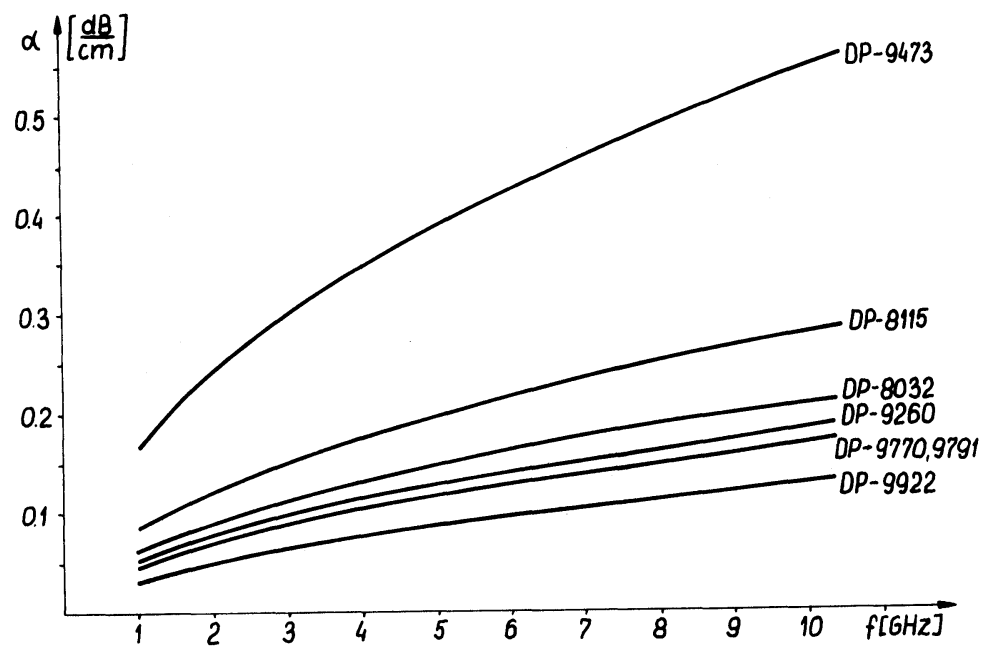

FIGURE 2 The relation between $\alpha=f(f)$ for ASL with $Z=50 \Omega$ for the model of homogeneous current density. Substrate: $96 \% \mathrm{Al}_{2} \mathrm{O}_{3}, h=0.5 \mathrm{~mm} \varepsilon_{r}=9.5$. 


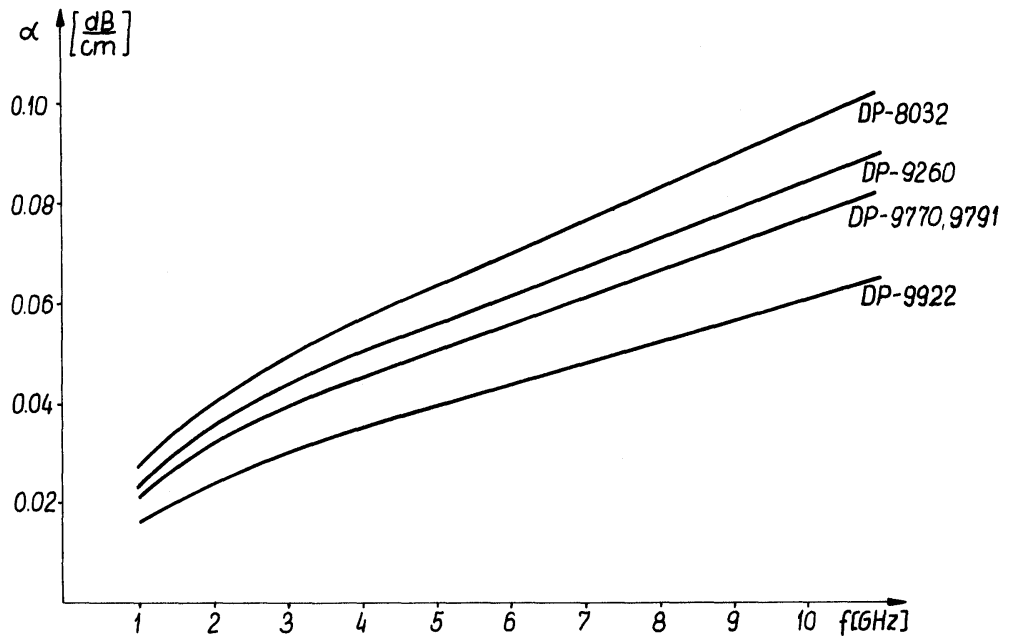

FIGURE 3 The relation $\alpha=f(f)$ for ASL with $Z_{0}=50 \Omega$ for M. V. Schneider's model (2). Remaining parameters-as in Figure 2.

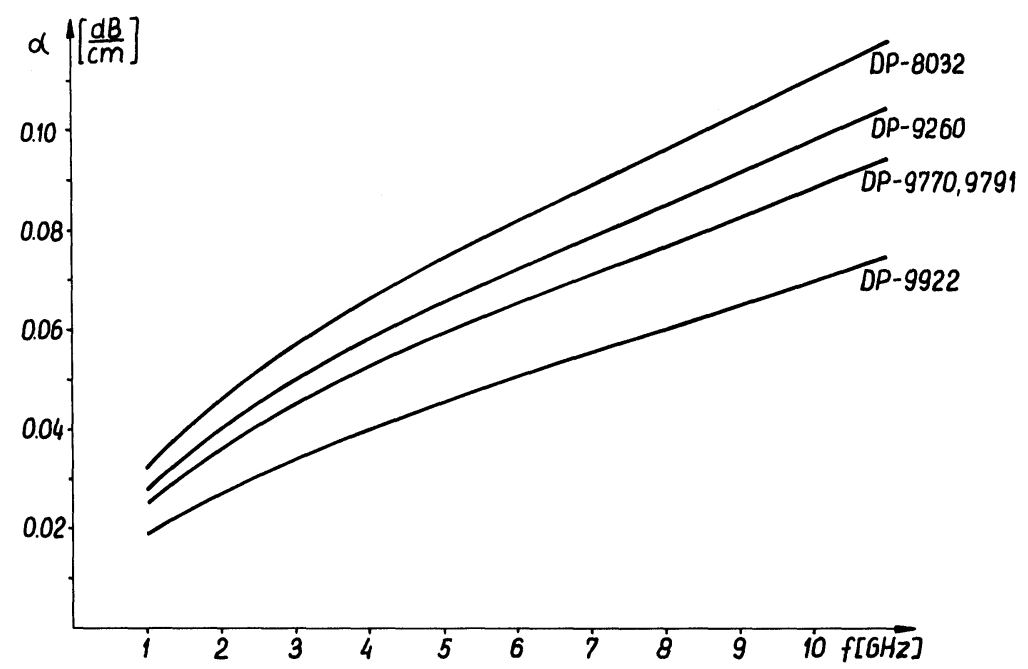

FIGURE 4 The relation $\alpha=f(f)$ for ASL with $Z=50 \mathrm{Ohm}$ for R. A. Pucel's model (2). Remaining parametersas in Figure 2. 


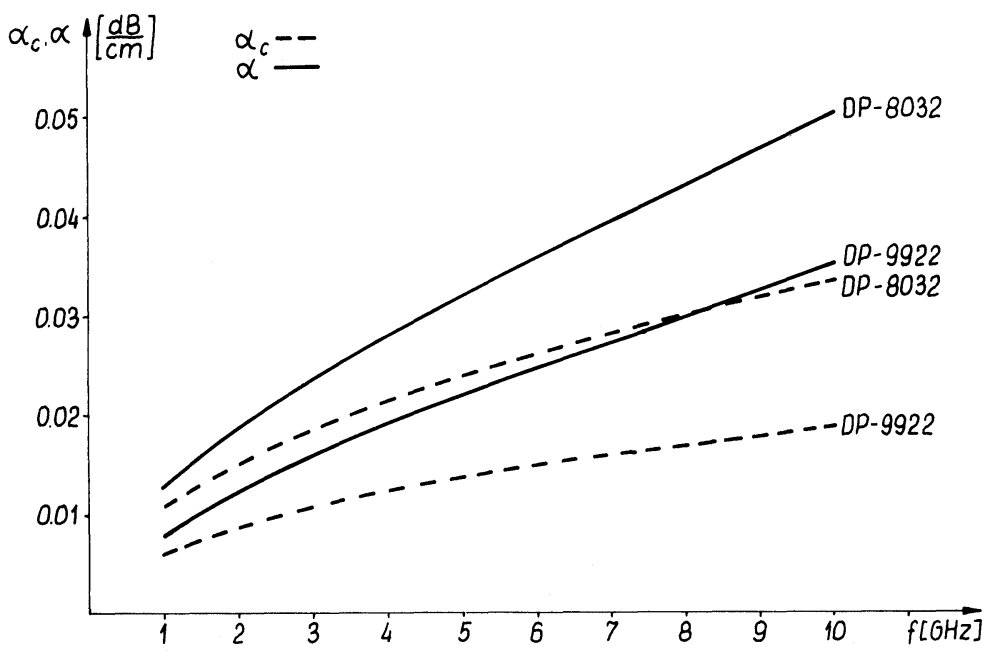

FIGURE 5 The relations $\alpha_{c}=f(f)$ and $\alpha=f(f)$ computed from R. A. Pucel's model (2). Substrate: steatite ceramics with $h=1.5 \mathrm{~mm}, \varepsilon_{r}=7.2, \operatorname{tg} \delta=8.10^{-4}, Z_{0}=30 \Omega$.

as pastes applicable to thick-film (MIC(3)). When copper pastes and low loss substrates are used it is not possible to ignore the losses in the dielectric $\alpha_{d}$ in computations. In general the losses in the dielectric may constitute a considerable percentage of total losses in ASL. This is shown in Figure 5. The fraction of losses $\alpha_{d} / \alpha=28.6 \%$ for the DP9922 paste at $f_{0}=1 \mathrm{GHz}$ and increases together with the increase of frequency.

\section{TESTING OF COPPER PASTES DP9922 AND DP9925 $3,4,5$}

In testing the usefulness of copper pastes for their application in MIC, strip resonators shown diagrammatically in Figure 6 and 7 were used.

The following design criteria were adopted:

1) Wave impedance $Z_{0}=50 \Omega$

2) Work frequency band $F=1-12 \mathrm{GHz}$

3) Substrate material-alumina ceramics $96 \%$

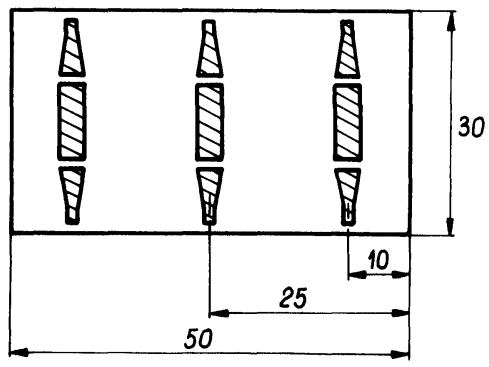

FIGURE 6 Rectangular strip resonators $85 \times 50 \mathrm{~mm}$.
4) Thickness of printed films $t=15-20 \mu \mathrm{m}$

5) Use of copper compositions DP9922 and DP9925.

In the designing of the resonators a numerical method of parameter computation was used. The computer programme was written in the Fortran 1900 language. (See Ref. 2.) In the programme the results obtained in (2) were used. Reference 2 was concerned with the influence of the discontinuous structure of thick films on mathematical models used in computing MIC parameters. Complex tests have been made
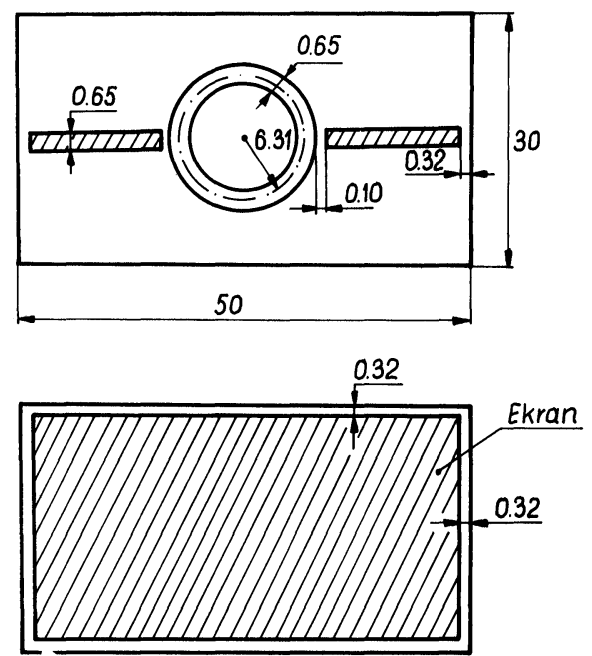

FIGURE 7 Ring resonator $85 \times 95 \mathrm{~mm}$. 


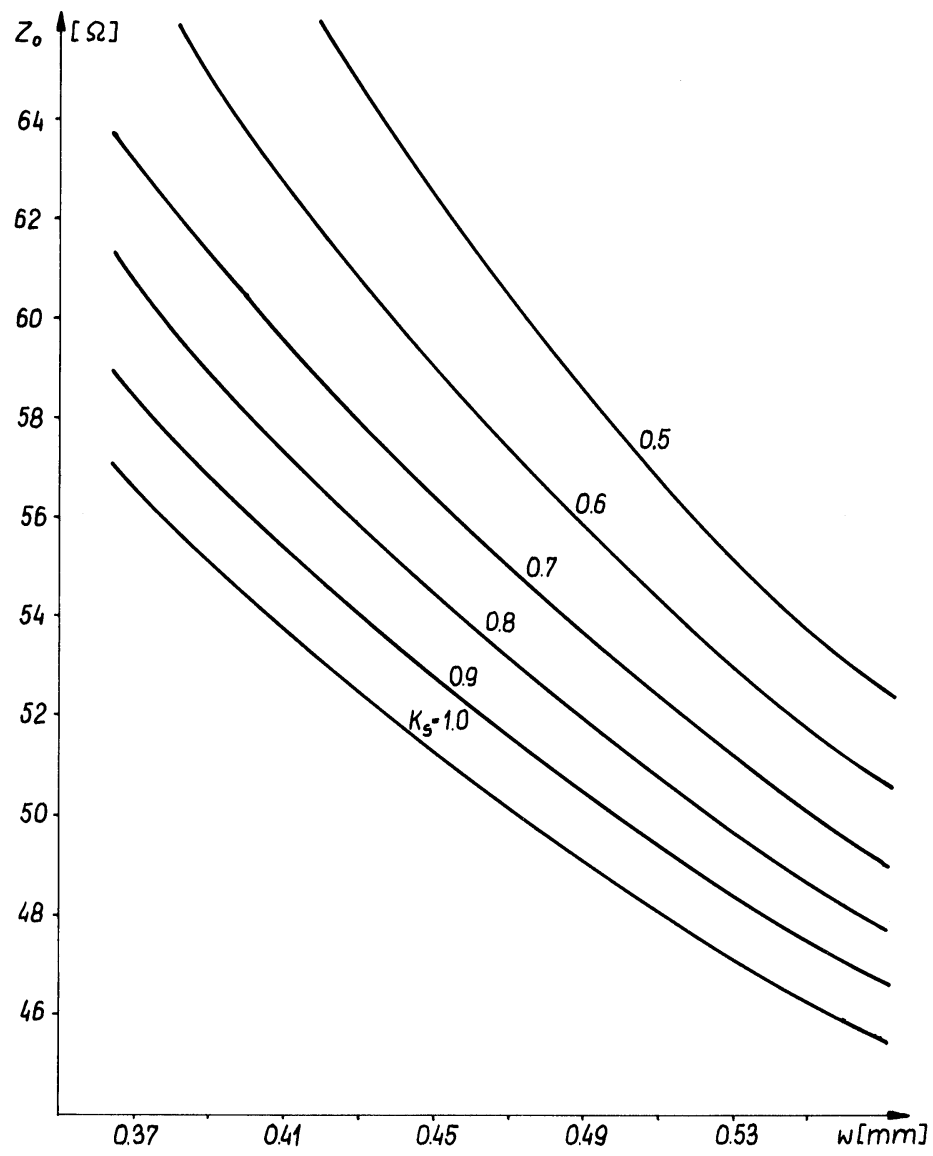

FIGURE 8 The relation $Z_{0}=f(w)$ at $K_{s}=$ const.

concerning this phenomenon, ${ }^{2}$ and the work introduced a new coefficient of surface covering " $K_{s}$ ", defined in Refs. 2 and 4. The influence of this coefficient on wave impedance is given in Figure 8.

As can be seen, the influence is considerable. The strip resonators were made by means of precise screening, with the use of the microscopic orientation of the screens. The edges of the paths of the resonators were subjected to laser dimension of trimming in order to improve the rectangularity of their cross sections. ${ }^{3}$ The firing was done in an atomsphere of nitrogen in a six-zone furnace produced by B.T.U. ${ }^{3,5}$.

An example of a profilogram made across a conductive strip of ASL is given in Figure 9. The resonators were tested transmissionally by means of a network analyser HP-8411. After converting the values of the quality factor $\mathrm{Q}$-obtained for different resonant frequencies -into values of unit attenuation $\alpha=f(f)$,
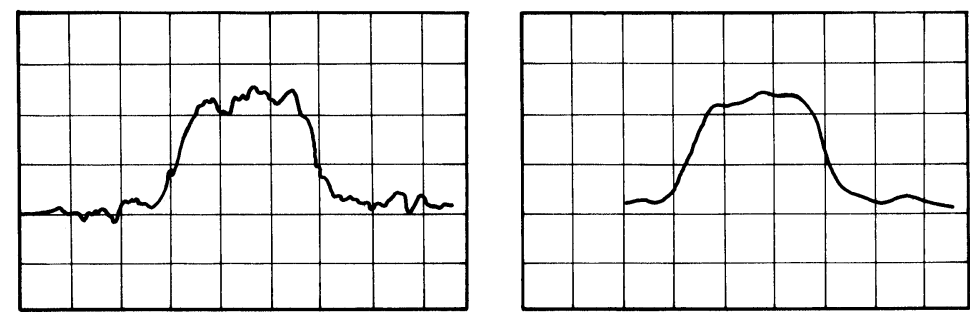

FIGURE 9 Profilogram of main ASL strip printed with DP9922/Cu. Magnification: $X=50 x, Y=200 x$. 


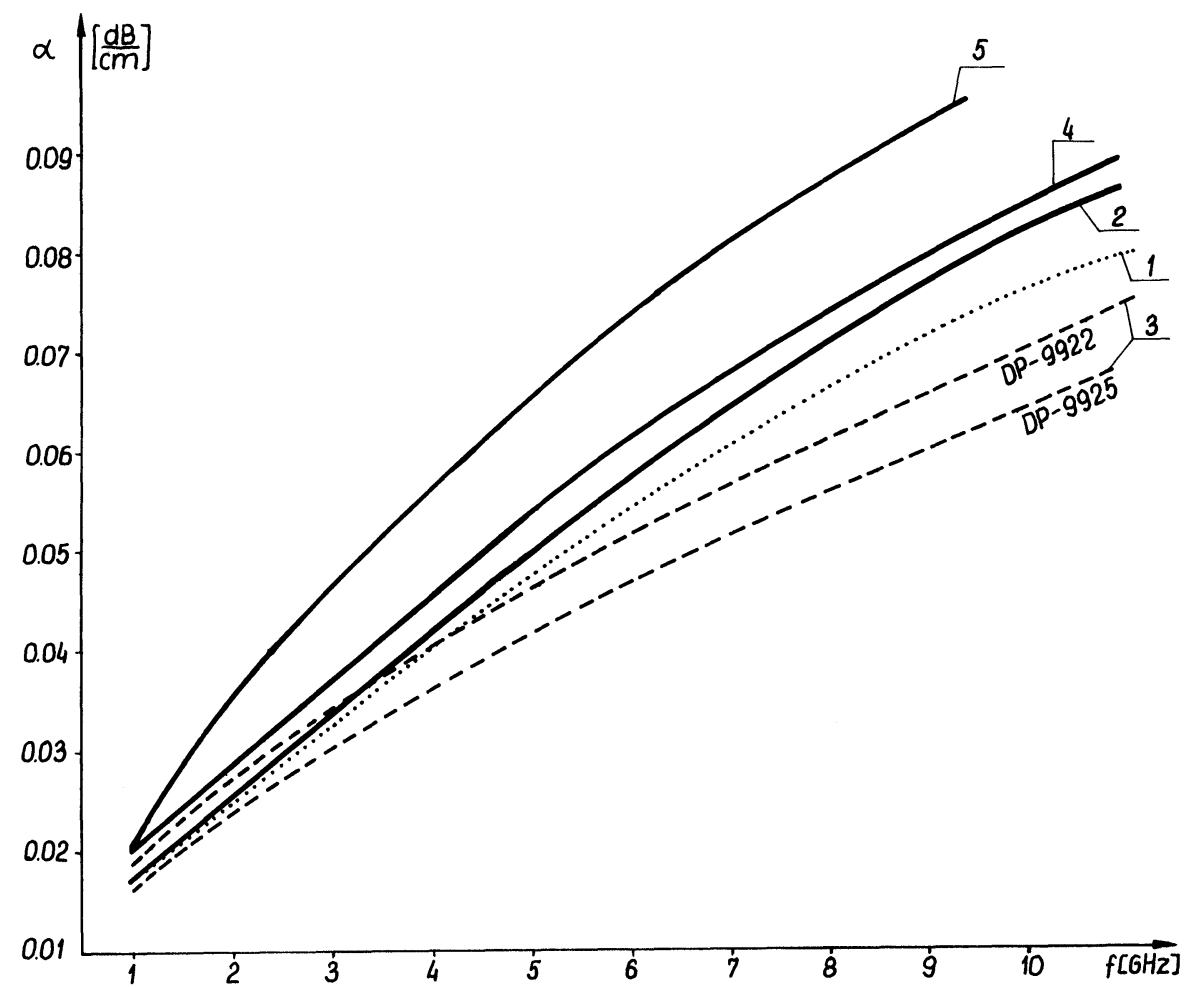

FIGURE 10 Frequency characteristics for attenuation in ASL obtained for copper pastes compared with other materials and technologies of ASL manufacturing, where:

1 - Cr-Au thin-film on alumina substrate (6)

2 - Copper thick film on alumina substrate, according to the authors of (6)

3 - Copper thick-film from Du Pont paste on alumina substrate-obtained by the authors of this paper.

4 - Copper thick-film on alumina substrate according to (6)

$5-10 Z$-Copper on Epsilam 10 or 6010 according to (6).

they are represented in the diagram of Figure 10. A comparison of the frequency characteristics of attenuation obtained for Du Pont copper pastes with other materials of this type was made. ${ }^{4,6}$ On analysis of the diagrams obtained one can see that the Du Pont copper pastes enumerated above meet the requirements in the tested microwave bands. Especially good parameters are given by the DP9925 paste, which has very low losses.

The results obtained for the thick film resonators can be compared with equivalent ones obtained with the use of the thin film technology. One should hope therefore that in the near future thick film copper pastes will be generally used in MIC.

\section{ACKNOWLEDGEMENTS}

The authors express their thanks to their dear departed Colleague, the late lamented Dieter Schuerlein a representative of the Du Pont Company in West Germany, who contributed considerably to the present paper. Whilst treasuring him in our memory, we express our deep sorrow to his Family and colleagues at Du Pont.

\section{REFERENCES}

1. J. Caber, J. J. Gondek, M. A. Wójcicki, 'Problems Occuring in the Production of MIC and ther prospects', 16th-ISHM Conf., May 1980, Oulu, Finland.

2. J. J. Gondek, 'The influence of thick-film microcircuits construction for frequential parameters of microwave asymetrical striplines, Doctor's dissertation, $M$ \& M University 1980, Krakow, Poland.

3. J. J. Gondek, 'The Possibilities of Producing Thick-Film Microwave Stripline Resonators made with Du Pont/USA/Compositions operating within a Band of 4-8 GHz; Design and Manufacture', Proceedings of 29th Electronic Components Conference, May 1979, New Jersey. 
4. J. J. Gondek, J. Caber, M. A. Wójcicki, 'New Thick-Film Microwave Elements for MIC', Proceedings of 31st Electronic Components Conference, May 1981, Atlanta.

5. Wojcicki, M. Rachtan, Zb. Bylo, A. Kosiński, 'Utlenialność Proszku Miedzi w Swietle Badań
Deriwatograficznych', Rudy, Metale Niez̀elazne R.19, 1974, Nr 5, Katowice, UKD 669.3.046.5-492.2.

6. M. D. Kline, T. M. Nelson, 'Low Cost Large Substrates for Microwave Integrated Circuits', Proceedings of ISHM Conference, October 1980 New York. 

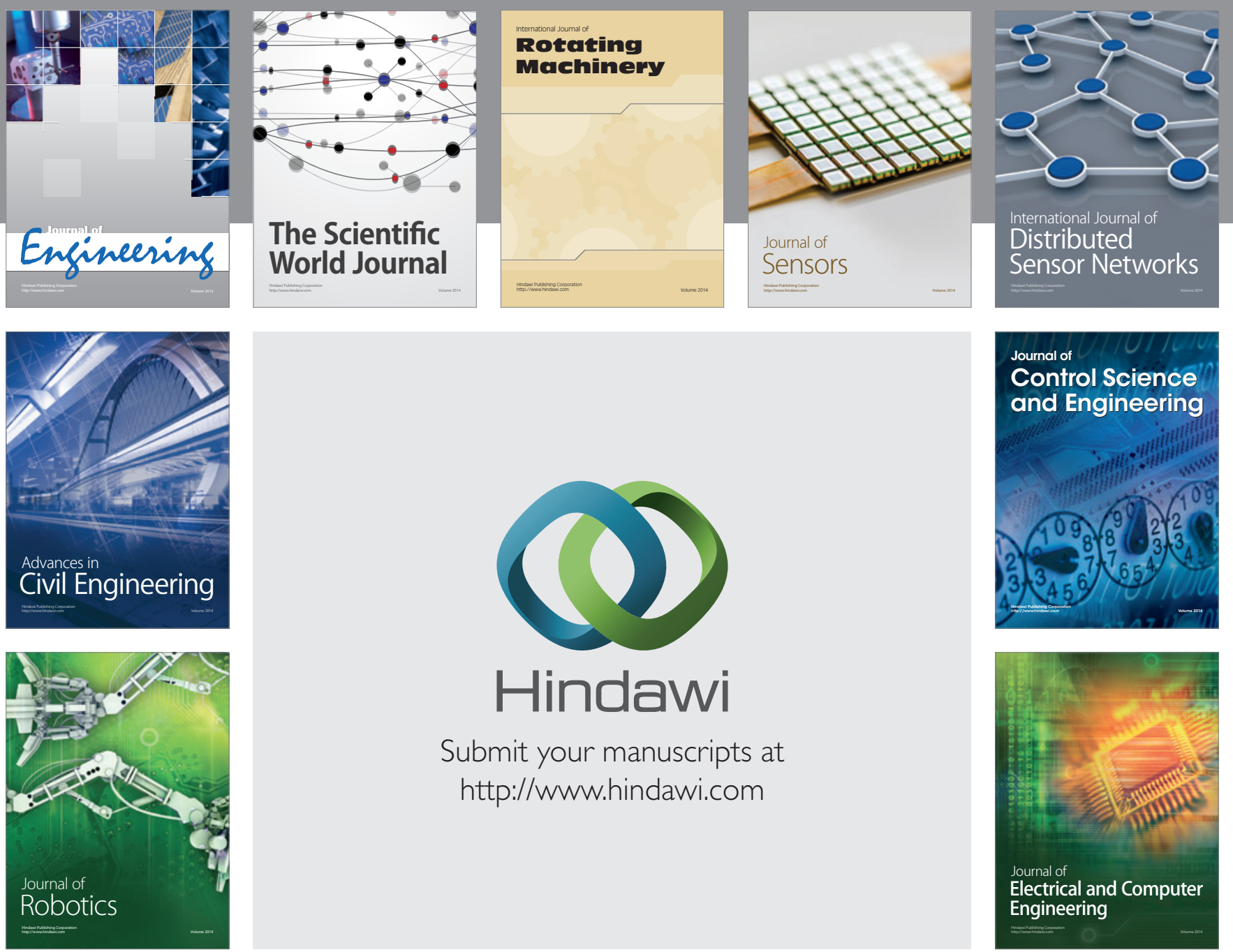

Submit your manuscripts at

http://www.hindawi.com
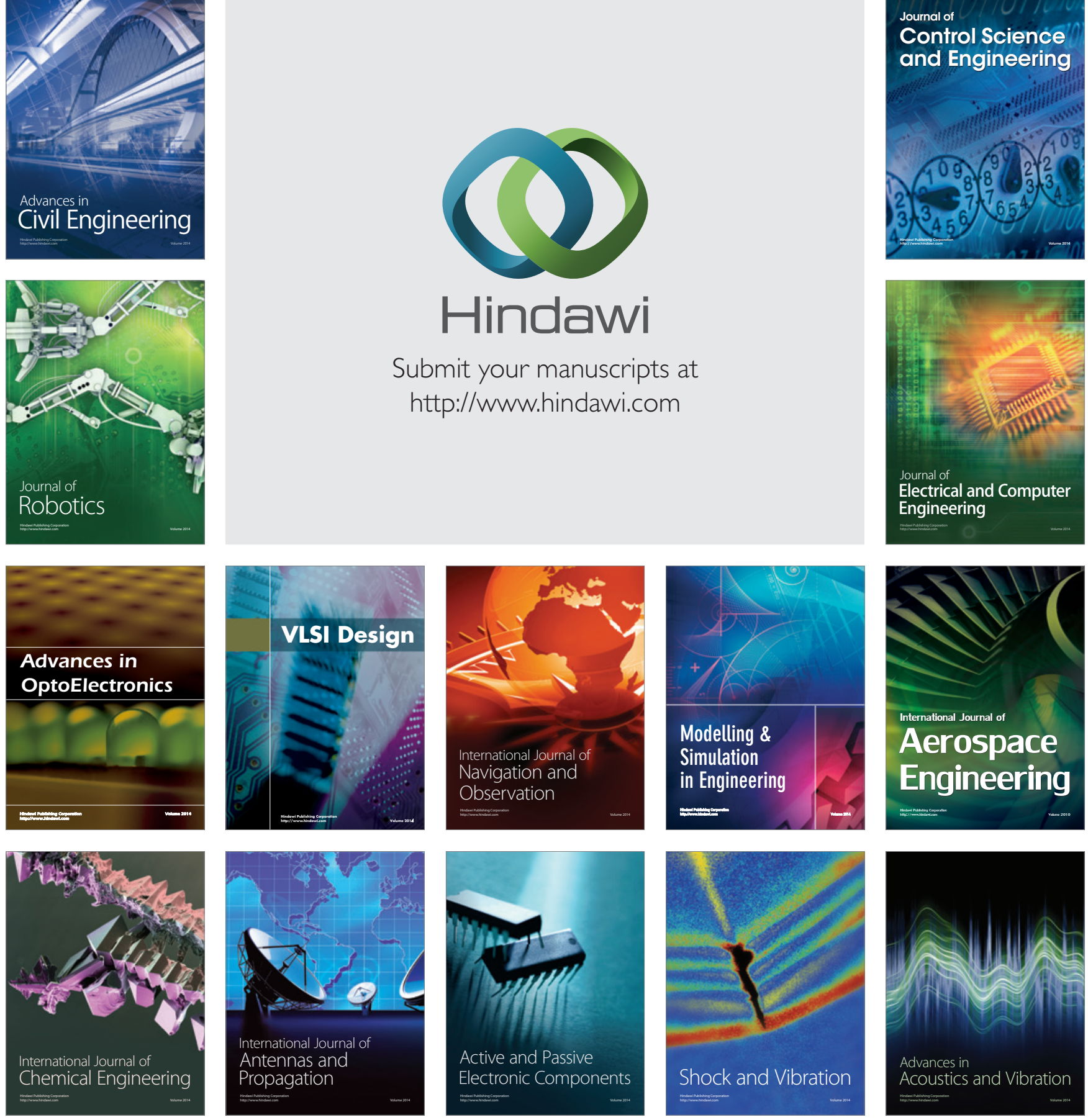